\title{
OPTIMIZATION OF PROCESS PARAMETERS FOR CONICAL AND CYLINDRICAL TOOLS WITH GROOVES IN FRICTION STIR WELDING PROCESS
}

\author{
Suresha, C. N..*; Rajaprakash, B. M.** \& Sarala Upadhya** \\ ${ }^{*}$ Research Scholar, Department of Mechanical Engineering, University Visvesvaraya College \\ of Engineering, Bangalore University, 560001 INDIA \\ ${ }^{* *}$ Professor, Department of Mechanical Engineering, University Visvesvaraya College of \\ Engineering, Bangalore University, 560001 INDIA \\ E-mail: aishuchetu@yahoo.com; bmruvce@yahoo.co.in; sarala_upadhya@hotmail.com
}

\begin{abstract}
:
Friction Stir Welding is a recent emerging welding technology invented by The Welding Institute (TWI) in 1991. This has evolved into a process focused on joining of arcweldable (5xxx and 6xxx) and difficult to weld (2xxx and $x x x$ ) aluminum alloys. The present study is aimed to determine the optimum process parameters and identify the most influencing significant parameter along with percentage contribution of each parameter on tensile strength of Friction Stir Welded AA 7075-T6 aluminum joints by conducting specific number of experiments using Taguchi approach. In this study, tool pin profiles having conical and cylindrical head with grooves are used. It has been observed that the tool rotational speed exhibits more influence on tensile strength in both the tools. Further the tool having conical profile results in better joint efficiency than the tool having cylindrical profile. The method described in this paper for the prediction of tensile strength and optimization of process parameters can eliminate the need for performing more experiments on the basis of conventional trial and error method.
\end{abstract}

Key Words: FSW, FSW Parameters, Tool Profile, Tensile Strength, Joint Efficiency, Taguchi

\section{INTRODUCTION}

The technology of Friction Stir Welding (FSW) process invented by The Welding Institute (TWI) in 1991 has resulted in joining of metals based on solid state diffusion. This process has the advantage that there are no defects in the welds due to fusion welding of metals. Figure 1 shows the working principle of FSW process and Figure 2 shows different stages in FSW process. 


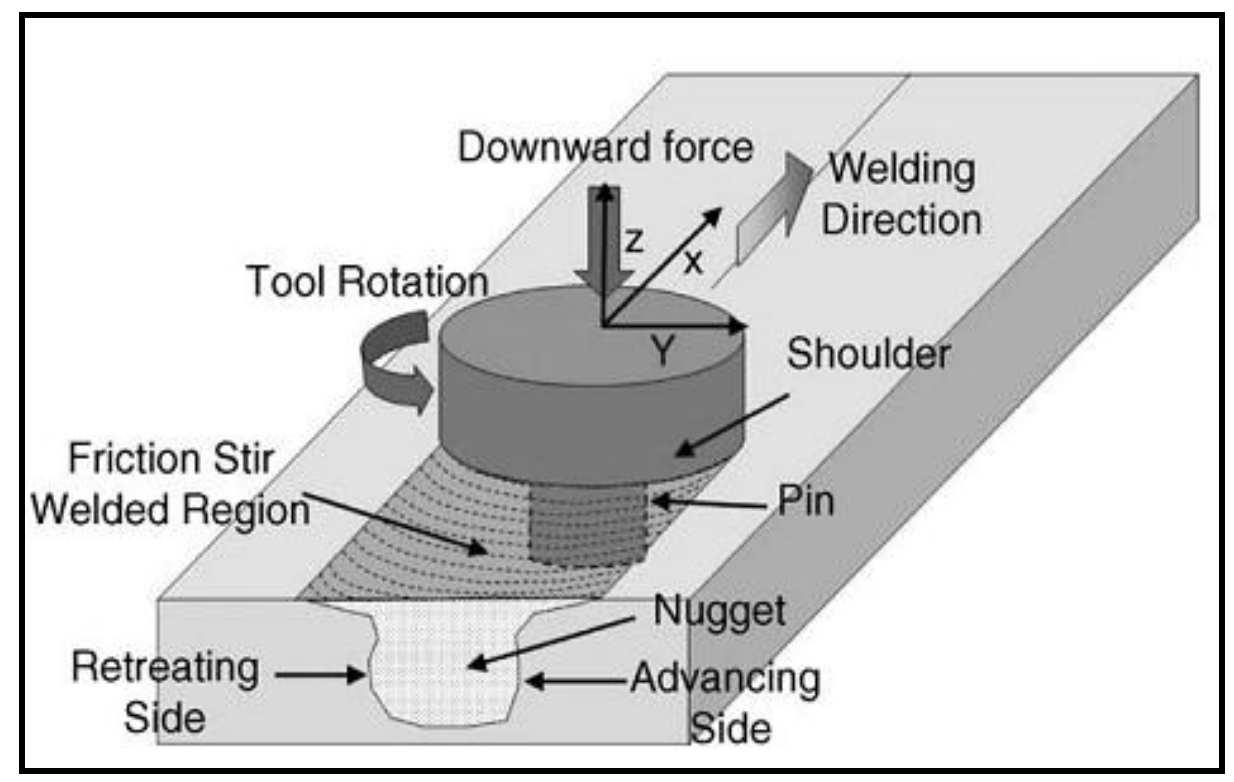

Figure 1: Principle of FSW process.

Heat of friction is initially generated through the pin (Figure 2a) of the welding tool which brought into contact with material being welded along the weld line (Figure $2 b$ ). The welding tool is then impressed in the work piece softened by the heat of friction as long as shoulder is in contact (Figure 2c). The zone including the weld line is then stirred through the rotating welding tool while being moved along the weld line (Figure 2d). The tip of the welding tool is generally called a 'pin' or 'probe' and is provided with shoulder [1]. The tool shape determines the heating, plastic flow and forging pattern of the plastic weld metal. The tool material determines the rate of heating, tool strength and working temperature, and ultimately determines the materials which can be friction stir welded [2]. The material grade of the welding tool must be such that its strength can be maintained at temperatures ensuring work piece softening during welding. FSW welding parameters include the 'tool rotational speed' 'weld traverse speed' (running speed) and 'plunge depth' (tool insertion depth). These parameters act as the principal welding conditions. FSW is free from generation of welding defects, such as blowholes and cracks, formed during fusion welding, although tunnel-like defects may occur if the running speed and rotational speed are wrongly combined. This type of defect is more likely to occur at a high running speed in relation to the rotational speed, i.e. when the material is inadequately stirred as the rotary tool moves along the weld line. However, a good-quality defect-free weld joint can be easily obtained relatively through appropriate selection of the tool rotational speed and weld traverse speed combination. The relationship between the tool rotational speed and weld traverse speed is an indication to prevent the occurrence of macroscopic welding defects which depends on the material being welded [2]. 


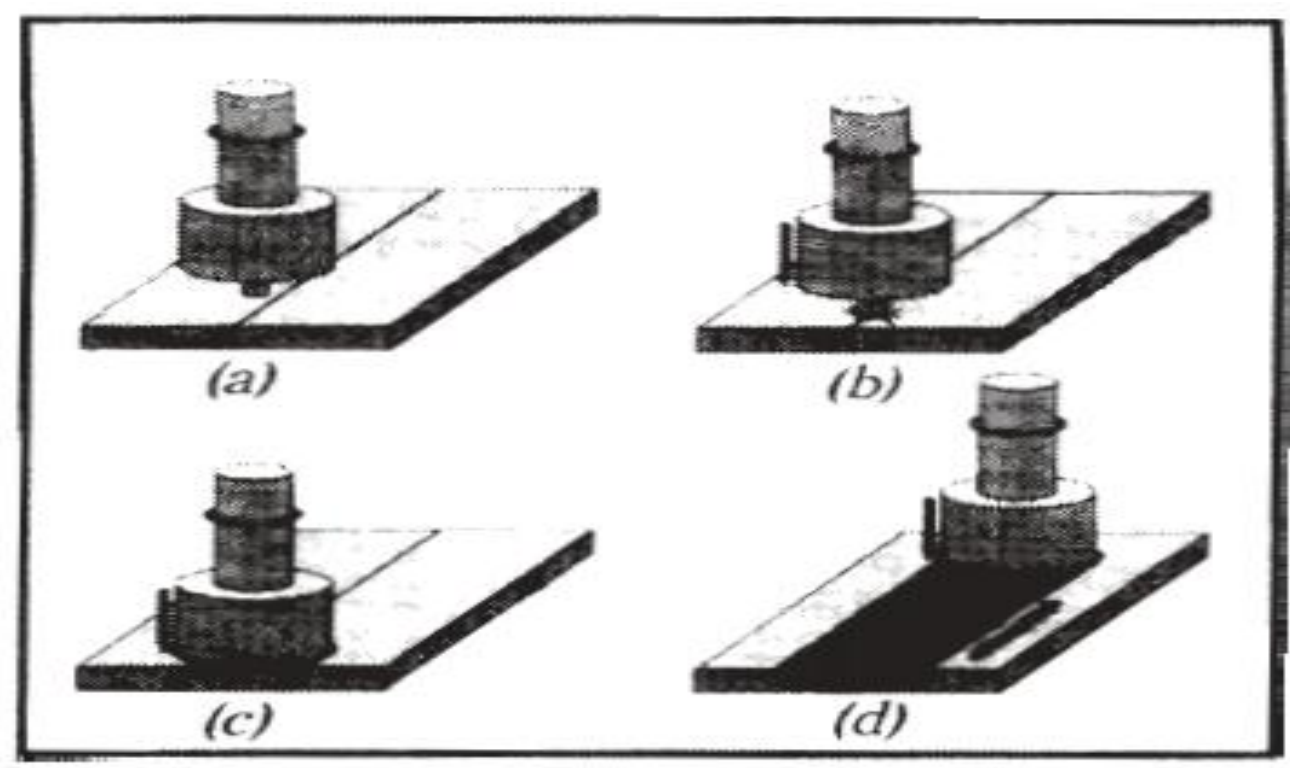

Figure 2: Stages of FSW welding process.

Originally the FSW was developed for joining high strength aluminum alloys produced by powder metallurgy. The reported users of FSW include Boeing Company, Lockheed Martin, NASA, Airbus, Rolls Royce, GE, US Navy, Mitsubishi, Kawasaki, Fokker, etc. This technology is capable of joining a range of similar materials as well as dissimilar materials. Current state of the art of this technology in the domain of low melting point materials such as aluminum alloys has matured up to the point where this technology is well-suited for commercial and military aircrafts application. A wide range of different grades of aluminum alloys are capable of being welded by this technology resulting in better properties than those produced using fusion welding [3]. Precipitation hardenable aluminum alloys of $7 \mathrm{XXX}$ series, such as 7075 are used extensively in aerospace industries. These alloys are difficult to join by conventional fusion welding techniques. Hence realizing a fusion-welded joint in such alloys without impairing the mechanical properties is a difficult task for a welding engineer. Consequently he/she has to rely on rivets and fasteners with substantial increase in fabrication cost and structure weight [4]. Many investigators have made investigations on the relationship between base metal properties and friction stir welding process parameters [5], the effect of welding processes like GMAW (Gas Metal Arc welding), GTAW (Gas Tungsten Arc Welding), and FSW on tensile properties [6], influence of pin profile and rotational speed of the tool on the formation of friction processing zone[7], influence of tool pin profile and axial force on the formation of friction stir processing zone [8], influence of tool geometry in FSW with specific reference to microstructural development, joint efficiency [9] and optimization of FSW parameters to maximize the tensile properties [10]. Literature reveals that the predominant factors that affect the tensile strength of friction stir welded aluminum alloys are tool pin profile, tool rotational speed, weld traverse speed and plunge depth. However it is evident from literature that the studies on joining of AA 7075 - T6 aluminum alloy in analyzing the influence of tool pin profiles, welding parameters on mechanical properties is not been reported. Hence in this investigation studies are made to analyze the effect of welding process parameters on tensile strength and joint efficiency of FSW joints for two type's tool of pin profiles namely conical and cylindrical tool head with grooves.

\section{TAGUCHI METHOD}

Taguchi method is an efficient problem solving tool, which is used to improve the performance of a process / product or a system without having to conduct a large number of experiments. This saves time and reduces the cost of experimentation [11]. This method has 
been applied for carrying out robust design of processes and products and solving many complex problems in manufacturing industries. It combines the experimental design theory and quality loss function concept for solving problem. Complex situations arise when a large number of process parameters to be dealt with, as the number of experiments to be conducted have to match with the number of influencing parameters, to arrive at any tangible conclusion. In such cases, it is possible to determine the most influential parameter for improving the overall efficiency of any process using Taguchi technique by carrying out few experiments. Another advantage of Taguchi technique is that the optimum processes parameters thus obtained are insensitive to the variation in the environmental condition and other noise factors. Taguchi method uses a special design of orthogonal array to study the entire process parameter space with only a small number of experiments. Taguchi defines three categories of quality characteristics in the analysis of Signal /Noise ratio ( $\mathrm{S} / \mathrm{N}$ ratio). They are categorized as (i) the lower is better, (ii) the higher is better and (iii) the nominal is best. The $\mathrm{S} / \mathrm{N}$ ratio for each combination of the process parameters is computed based on Signal Noise analysis. A larger $\mathrm{S} / \mathrm{N}$ ratio corresponds to better quality characteristics, in all the above mentioned three categories. Therefore, the optimum level of process parameters is the level of highest $\mathrm{S} / \mathrm{N}$ ratio. Further, a statistical analysis of variance (ANOVA) can be performed to identify the process parameter which is statistically significant for each considered quality characteristics of the process. ANOVA is a collection of statistical models, and their associated procedures, in which the observed variance is partitioned into components due to different explanatory variables. The initial techniques of the AVOVA were developed by the statistician and geneticist R. A. Fisher [12] in the 1920s and 1930s, and is sometimes known as Fisher's ANOVA or Fisher's analysis of variance, due to the use of Fisher's F-distribution as part of the test of statistical significance. ANOVA is mainly carried to analyze the statistical significance of different factors at different levels of the response variables. It is performed based on the design of experiments and all the response variables.

\section{SELECTION OF ORTHOGONAL ARRAY (OA)}

The two points considered before selecting a particular OA for conducting experiments are: (i) The number of parameters and interactions of interest and (ii) The number of levels for the parameters of interest. The non-linear behavior, if it exists among the process parameters, can only be studied if more than two levels of the parameters are used. Therefore, each parameter was analyzed at three levels. Each of the three level parameters has two degrees of freedom (DOF) (since DOF is equal to Number of levels minus one). The total DOF required for three parameters each at three levels is six. As per Taguchi's method, the total DOF of selected OA must be greater than or equal to the total DOF required for the experiment. So L9 OA having 8 degrees of freedom was selected for the present work [12]. The scope of the present work is limited to study only the first order interactions of FSW process parameters.

\section{EXPERIMENTAL DETAILS}

Rolled plates of AA7075-T6 aluminum alloy of $5 \mathrm{~mm}$ thickness were used in the present investigation. The composition and mechanical properties of the alloy are shown in Table I and Table II respectively. 
Table I: Chemical composition of Aluminum Alloy AA7075 -T6.

\begin{tabular}{|c|l|l|l|l|l|l|l|l|}
\hline Alloy & Zn \% & Mg \% & Cu \% & Cr \% & Mn \% & Ti \% & Si \% & Al \% \\
\hline $\begin{array}{c}7075 \\
\text { T6 }\end{array}$ & $5.1-6.1$ & $2.1-2.9$ & $1.2-2$ & $0.18-0.28$ & Max 0.3 & Max 0.2 & Max 0.4 & $\begin{array}{c}87.1- \\
91.4\end{array}$ \\
\hline
\end{tabular}

Table II: Mechanical properties of Aluminum Alloy AA7075 -T6

\begin{tabular}{|c|c|c|c|c|}
\hline Alloy & Tensile strength (MPa) & Yield Strength(MPa) & Elongation \% & Hardness (VHN) \\
\hline 7075 T6 & 524 & 430 & 10 & 140 \\
\hline
\end{tabular}

Plates were cut into $75 \mathrm{~mm} \times 300 \mathrm{~mm}$ size to suit the clamps of FSW machine (conventional Milling machine) to prepare square butt joints. The initial joint configuration was obtained by securing the plates in position using mechanical clamps on FSW machine. Single pass welding procedure was followed to fabricate the joints. Non-consumable tools made of Hot Die Steel having conical and cylindrical tools with grooves were used to prepare the welded joints Figure 3.

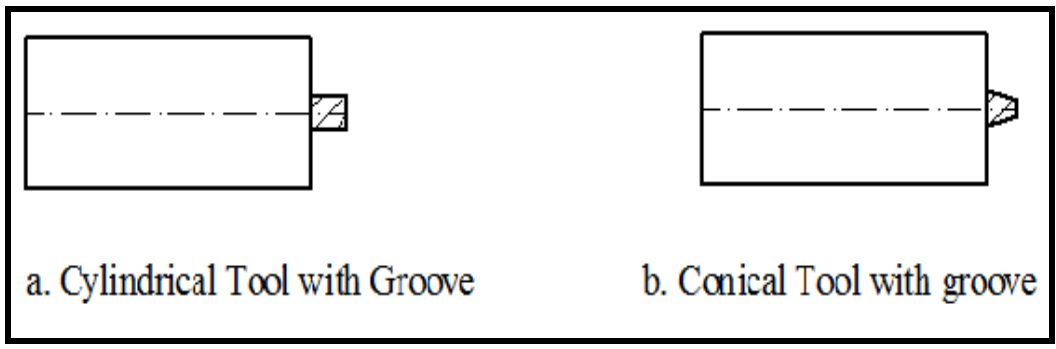

Figure 3: Line diagram showing FSW tools used in the study.

Trial experiments were conducted to determine the working range of welding parameters. The feasibility limits of the parameters were chosen in such a way that the FSW joints are free from any visible defects. The process parameters for welding namely tool rotational speed, weld traverse speed and plunge depth along with their levels selected and details of tool are given in Table III. Tensile specimens were prepared as per ASTME8/E8M-08 standard [13]. Tensile tests were carried out on a 20KN Electronic Tensometer (Make: Kudale Instruments, Model: PC 2000).

Table III: Welding process parameters \& Tool Dimensions.

\begin{tabular}{|c|c|c|c|c|c|c|c|}
\hline Levels & $\begin{array}{c}\text { A } \\
\text { Rotational } \\
\text { speed } \\
\text { (RPM) }\end{array}$ & $\begin{array}{c}\text { B } \\
\text { Weld Traverse } \\
\text { speed }(\mathrm{mm} / \mathrm{min})\end{array}$ & $\begin{array}{c}\text { C } \\
\text { Plunge depth } \\
(\mathrm{mm})\end{array}$ & $\begin{array}{l}\mathrm{D} / \mathrm{d} \text { ratio } \\
\text { of tool }\end{array}$ & $\begin{array}{l}\text { Pin length } \\
\quad(\mathrm{mm})\end{array}$ & $\begin{array}{l}\text { Tool Shoulder } \\
\text { diameter }(\mathrm{mm})\end{array}$ & $\begin{array}{c}\text { Pin } \\
\text { diamet } \\
\text { er } \\
(\mathrm{mm})\end{array}$ \\
\hline Level 1 & 900 (A1) & 40 (B1) & 4.93 (C1) & \multirow{3}{*}{$20 / 6$} & \multirow{3}{*}{75} & \multirow{3}{*}{20} & \multirow{3}{*}{6} \\
\hline Level 2 & 1120 (A2) & 50 (B2) & $4.96(\mathrm{C} 2)$ & & & & \\
\hline Level 3 & 1400 (A3) & 63 (B3) & $4.99(\mathrm{C} 3)$ & & & & \\
\hline
\end{tabular}




\section{RESULTS AND DISCUSSION}

\subsection{Signal to Noise ratio}

Tensile strength is the main response quality characteristic considered in this investigation describing the quality of welded joints produced by FSW. In order to assess the influence of welding parameters on the response (i.e. tensile strength), means and $\mathrm{S} / \mathrm{N}$ ratio for each control factor (tool rotational speed, weld traverse speed and plunge depth) were calculated using Mini Tab statistical software [14]. The signals are indicators of the effect on average responses and the noises are measures of the influence on the deviations from the sensitiveness of the experiment output to the noise factors. The appropriate $\mathrm{S} / \mathrm{N}$ ratio was chosen using previous knowledge, expertise, and understanding of the process. In this study, the $\mathrm{S} / \mathrm{N}$ ratio was chosen according to the criterion of the "higher is better", in order to maximize the response. In the Taguchi method, the $S / N$ ratio is used to determine the deviation of the quality characteristics from the desired value. The $S / N$ ratio $\eta_{\lrcorner}$(higher is better) in the $j_{\text {th }}$ experiment can be computed using the equation (1).

$$
\eta_{J}=-10 \log \left[1 / \mathrm{n} \Sigma \mathrm{Y}^{2}{ }_{\mathrm{ijk}}\right]
$$

Where $n$ is the number of tests

$Y_{i j k}$ is the experimental value of the $i^{\text {th }}$ quality characteristics in the $f^{\text {th }}$ experiment at the $k^{\text {th }}$ test.

The experimental results were then transformed into means of tensile strength and corresponding S/N ratio. Table IV shows the three levels of process parameters as per $L_{9}$ orthogonal array, the means of tensile strength and corresponding $\mathrm{S} / \mathrm{N}$ ratio for the tools considered.

Table IV: Tensile strength, joint efficiency \& S/N Ratio for experiments using conical \& Cylindrical Tool with grooves.

\begin{tabular}{|c|c|c|c|c|c|c|c|c|c|}
\hline \multirow{2}{*}{$\begin{array}{l}\text { SI } \\
\text { No. }\end{array}$} & \multirow{2}{*}{$\begin{array}{c}\text { Tool } \\
\text { rotational } \\
\text { Speed } \\
(\mathrm{rpm})\end{array}$} & \multirow{2}{*}{$\begin{array}{c}\text { Weld } \\
\text { traverse } \\
\text { Speed } \\
(\mathrm{mm} / \mathrm{min} \\
)\end{array}$} & \multirow{2}{*}{$\begin{array}{c}\begin{array}{c}\text { Plunge } \\
\text { depth } \\
(\mathrm{mm})\end{array}\end{array}$} & \multicolumn{3}{|c|}{ Conical Tool with groove } & \multicolumn{3}{|c|}{ Cylindrical Tool with groove } \\
\hline & & & & $\begin{array}{l}\text { Tensile } \\
\text { strength } \\
\left(\mathrm{N} / \mathrm{mm}^{2}\right)\end{array}$ & $\begin{array}{c}\text { Joint } \\
\text { efficiency } \\
(\%)\end{array}$ & $\begin{array}{l}\mathrm{S} / \mathrm{N} \\
\text { ratio }\end{array}$ & $\begin{array}{l}\text { Tensile } \\
\text { strength } \\
\left(\mathrm{N} / \mathrm{mm}^{2}\right)\end{array}$ & $\begin{array}{c}\text { Joint } \\
\text { efficiency } \\
(\%)\end{array}$ & $\begin{array}{l}\mathrm{S} / \mathrm{N} \\
\text { ratio }\end{array}$ \\
\hline 1 & 900 & 40 & 4.93 & 308.40 & 58.85 & 49.78 & 219.20 & 41.83 & 46.81 \\
\hline 2 & 900 & 50 & 4.96 & 290.00 & 55.34 & 49.25 & 312.50 & 59.63 & 49.89 \\
\hline 3 & 900 & 63 & 4.99 & 301.50 & 57.54 & 49.59 & 226.08 & 43.28 & 47.11 \\
\hline 4 & 1120 & 40 & 4.96 & 325.90 & 62.19 & 50.26 & 238.07 & 45.55 & 47.55 \\
\hline 5 & 1120 & 50 & 4.99 & 294.40 & 56.18 & 49.38 & 219.05 & 41.88 & 46.82 \\
\hline 6 & 1120 & 63 & 4.93 & 303.60 & 57.94 & 49.65 & 287.03 & 35.74 & 45.45 \\
\hline 7 & 1400 & 40 & 4.99 & 310.50 & 59.26 & 49.84 & 273.03 & 33.07 & 44.77 \\
\hline 8 & 1400 & 50 & 4.93 & 284.40 & 54.27 & 49.08 & 246.06 & 47.06 & 47.83 \\
\hline 9 & 1400 & 63 & 4.96 & 293.60 & 56.03 & 49.36 & 258.33 & 49.30 & 48.24 \\
\hline
\end{tabular}

The analysis of mean for each of the experiments will give the better combination of parameter levels that ensures a high level of tensile strength according to the experimental set of data. The mean response refers to the average value of performance characteristics for each parameter at different levels. The mean for one level was calculated as the average of all responses that were obtained with that particular level. The optimal level of process 
parameter corresponding to the highest $\mathrm{S} / \mathrm{N}$ ratio can be identified by from the plots as shown in Figure 4 and Figure 5 for conical grooved and cylindrical grooved tool respectively. Similarly Figure 6 and Figure 7 can be used to identify the optimum level of process parameters corresponding to tensile strength as output quality characteristics for conical grooved and cylindrical grooved tool respectively. The S/N ratios were also calculated using Win Robust (version 1.0) statistical software [15], which indicates that the maximum tensile strength was with a tool rotational speed of $1120 \mathrm{rpm}$, a weld traverse speed of $40 \mathrm{~mm} / \mathrm{min}$ and a plunge depth of $4.96 \mathrm{~mm}$ for conical grooved tool. Maximum tensile strength is with a rotational speed of $1400 \mathrm{rev} / \mathrm{min}$, a weld traverse speed of $50 \mathrm{~mm} / \mathrm{min}$ and a plunge depth of $4.96 \mathrm{~mm}$ for cylindrical grooved tool.

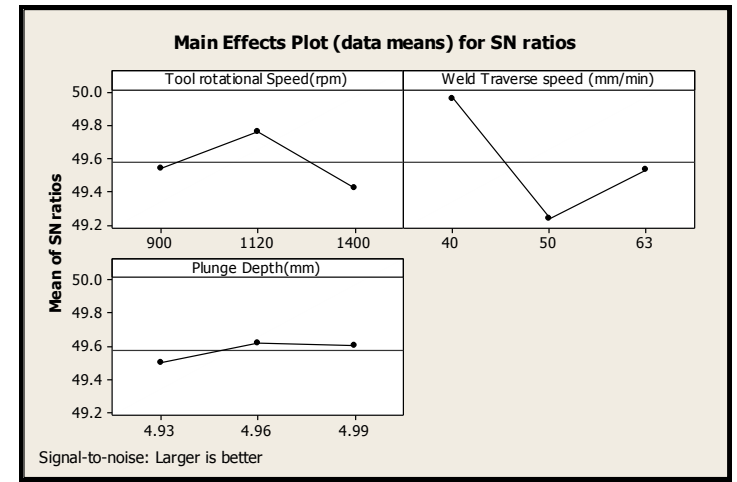

Figure 4: Main Effect Plot for $\mathrm{S} / \mathrm{N}$ ratios for Conical tool with groove.

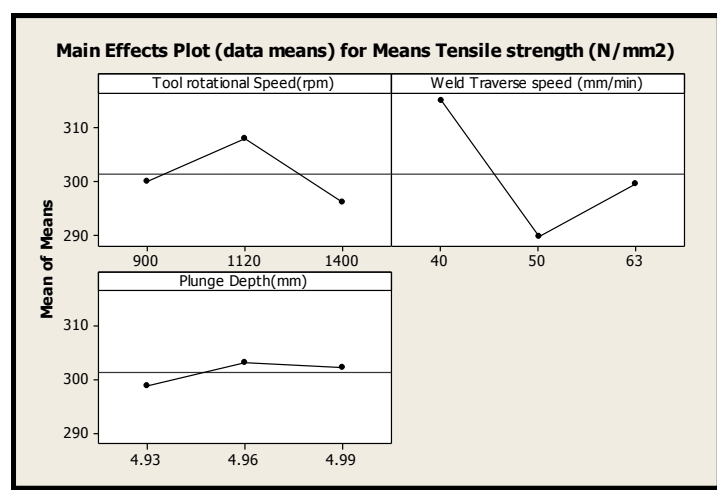

Figure 6: Main Effect Plot for and tensile strength for Conical tool with groove.

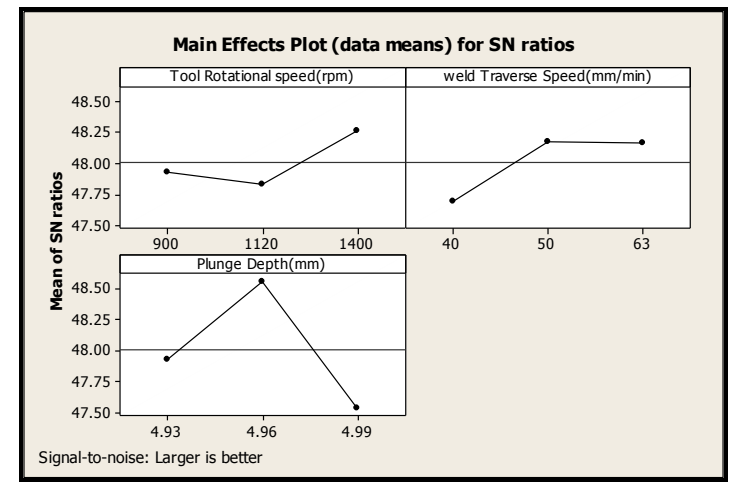

Figure 5: Main Effect Plot for $\mathrm{S} / \mathrm{N}$ ratios for Cylindrical tool with groove.

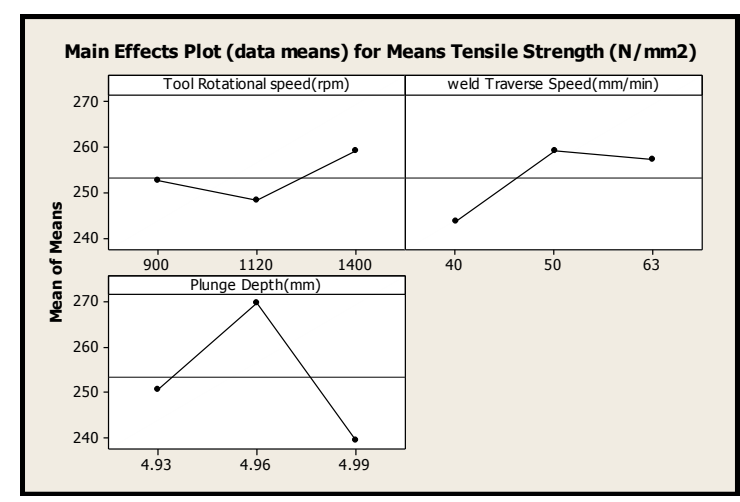

Figure 7: Main Effect Plot for and Tensile Strength for Cylindrical tool with groove.

\subsection{Analysis of Variance (ANOVA)}

ANOVA test was performed to identify the process parameters that are statistically significant. The purpose of the ANOVA test is to investigate the significance of the process parameters which affect the tensile strength of welded joints produced by FSW. ANOVA was performed using Win Robust software [15] and the results are summarized in Tables $V$ and VI for conical and cylindrical tools respectively. In addition, ' $F$ '- test has been used to determine the parameter that has more significant effect on the tensile strength. Usually, process parameters have a significant effect on the quality characteristics, when $F$ is large. The results of ANOVA indicate that the process parameters under consideration have different intensity of signifance affecting the tensile strength of FSW joints. 
Table V: Results of ANOVA for Conical Tool with Groove.

\begin{tabular}{|c|c|c|c|c|c|}
\hline Factor & DOF & Sum of squares & Mean sum of squares & Fcal & $\begin{array}{c}\% \\
\text { contribution }\end{array}$ \\
\hline A & 2 & 6390.25 & 3195.125 & 34.3 & 73.70 \\
\hline B & 2 & 1400.21 & 700.105 & 7.5 & 14.42 \\
\hline C & 2 & 440.94 & 220.47 & 2.4 & 3.02 \\
\hline Error & 2 & 186.56 & 93.28 & & 8.86 \\
\hline Total & 8 & 8417.96 & & & \\
\hline
\end{tabular}

Table VI: Results of ANOVA for Cylindrical tool with groove.

\begin{tabular}{|c|c|c|c|c|c|}
\hline Factor & DOF & Sum of squares & Mean sum of squares & Fcal & $\%$ contribution \\
\hline A & 2 & 977.25 & 488.62 & 24.7 & 74.09 \\
\hline B & 2 & 217.69 & 108.84 & 5.5 & 14.08 \\
\hline C & 2 & 31.25 & 15.62 & -- & -0.65 \\
\hline Error & 2 & 39.5 & 19.75 & & 3.12 \\
\hline Total & 8 & 1265.69 & & & \\
\hline
\end{tabular}

\section{INTERPRETATION OF EXPERIMENTAL RESULTS}

\subsection{Percentage of contribution}

The percentage contribution of the process parameter is the portion of the total variation observed in the experiment attributed to each significant factor. The percentage distribution is a function of the sum of squares for each significant item and it indicates the relative power of a factor to reduce the variation. If the factor levels are controlled precisely, then the total variation could be reduced by the amount indicated by the percentage of contribution. The percentage of contribution of the tool rotational speed, weld traverse speed and plunge depth is shown in Figure 8 for conical tool with groove and in Figure 9 for cylindrical tool with groove.

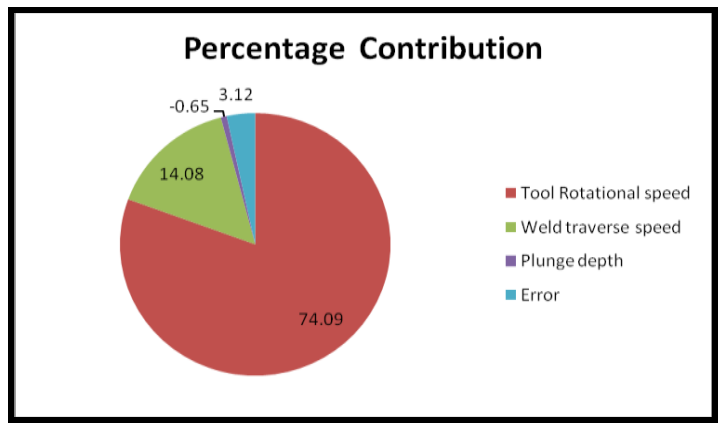

Figure 8: Percentage contributions of welding of parameters for conical tool with groove.

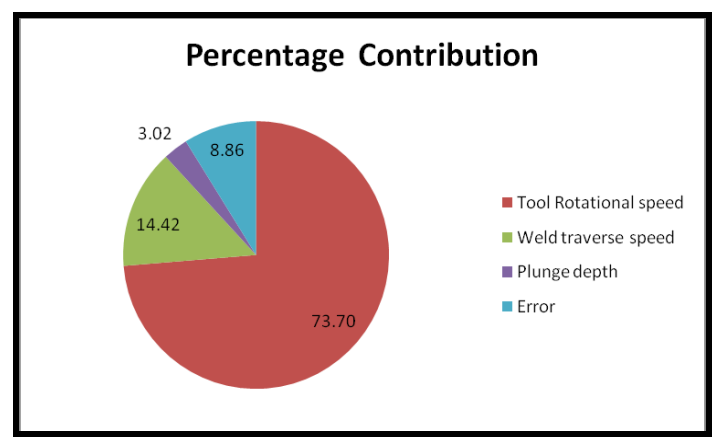

Figure 9 Percentage contributions of for parameters for cylindrical tool with groove.

It was observed that the percentage contribution of tool rotational speed is $74.09 \%$ in the case of the conical tool and $73.70 \%$ in case of cylindrical tool. The percentage contribution of tool rotational speed is higher, because the torque of the rotating the tool, along with surface contact of shoulder generates friction heating of the material, and the forces applied to the tool ensure the movement of the tool in the mass of the material, in the welding direction. The surfaces of the tool shoulder and the tool pin, which are in contact with the material edges, form friction couples which take direct part in the process of friction and formation of plastic flows. This activity seems to be more in both the tools. 


\subsection{Estimation of optimum performance characteristics}

Referring to Table IV, Figure 4 to Figure 7 and considering the highest values of S/N ratio and mean levels for the significant factors $A, B$ and $C$, the overall optimum combination of parameters obtained were A2, B1, C2 for conical tool and A3, B2, C2 for cylindrical tool. After conduction of experiments, to determine the optimal combination of process parameters, it was found that, there can be two possibilities that can exist are as follows: $i$. the optimum combination of parameters is identical to one of combinations in the experiments conducted. ii. The optimum combination of parameters is not included in the experiments conducted. In the present work, optimal combination of parameters for conical tool satisfies the first possibility and for cylindrical tool satisfies the second possibility cited above. This indicates that the selection of considered for experiments parameters in present study is appropriate [7]. The optimum value of tensile strength is predicted at the selected levels of significant parameters. This is done by using Win Robust software. The details of analysis are shown in Figure 11 and Figure 12 for conical and cylindrical tool with groove respectively.

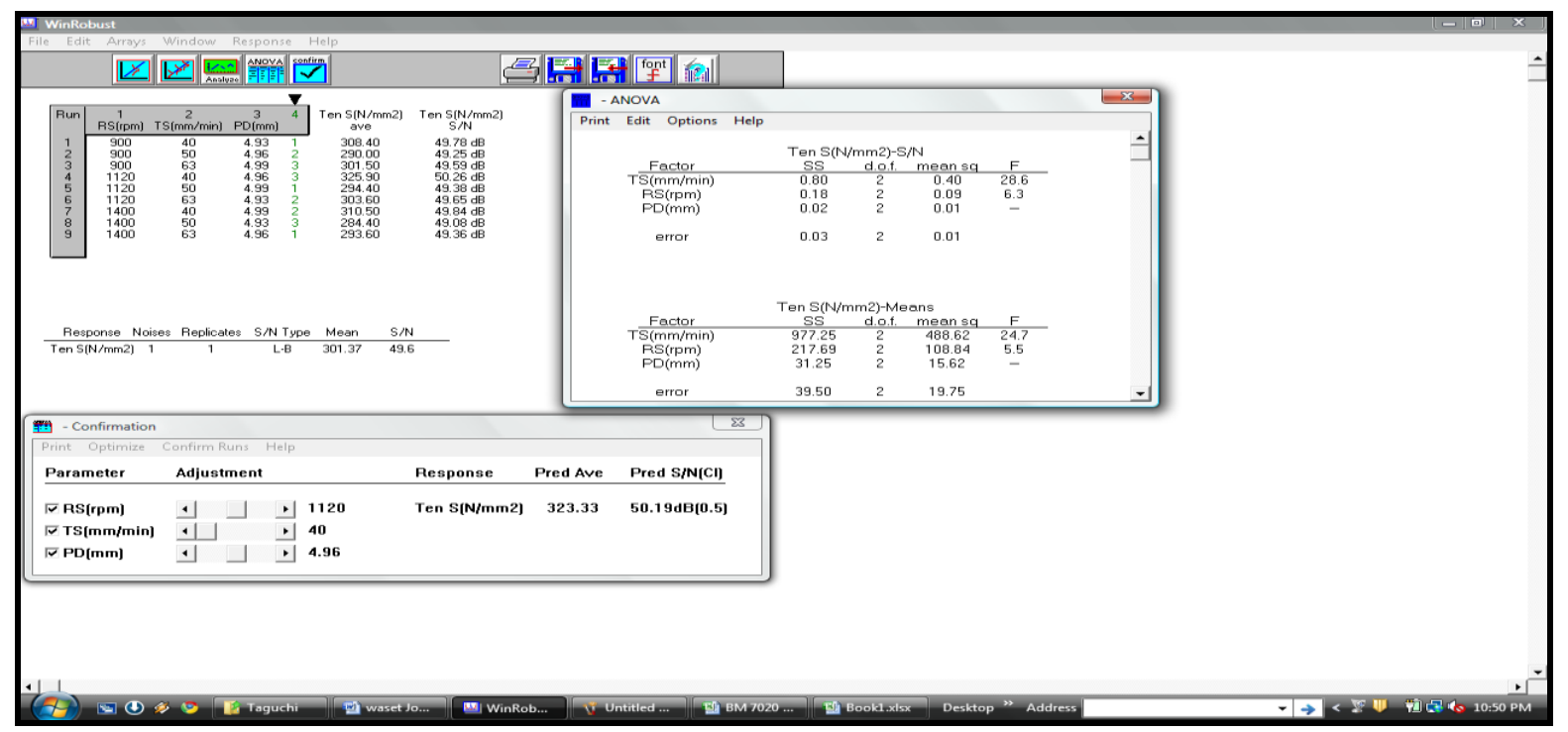

Figure 11: Results of ANOVA for Conical tool with groove.

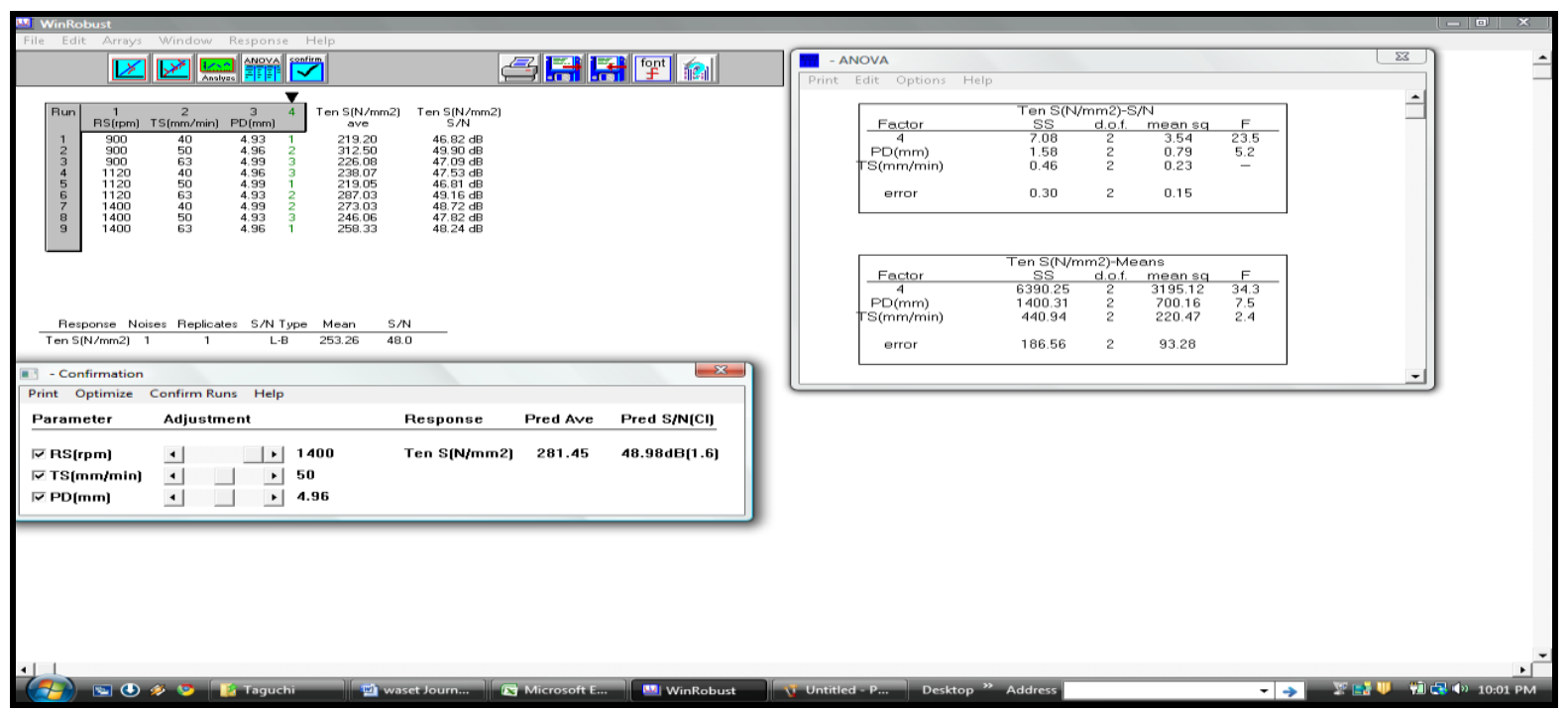

Figure 12: Results of ANOVA for Cylindrical tool with groove. 


\section{3 Confirmations Tests}

After the selection of optimal level of process parameters, the final step is to predict and verify the improvement in quality characteristics of FSW process, for these parameters. The predicted $\mathrm{S} / \mathrm{N}$ ratio for optimal welding parameters and the corresponding tensile strength and efficiency are presented in Table VII and Table VIII for conical and cylindrical tools respectively. The joint efficiency of conical and cylindrical tool for initial parameters, optimal estimated parameters and optimal experimental parameters are presented in Figure 10.

Table VII: Results of Confirmation test of welded joint using Conical Tool with groove.

\begin{tabular}{|c|c|c|c|}
\hline & \multirow{3}{*}{$\frac{\text { Initial parameters }}{\mathrm{A}_{2} \mathrm{~B}_{2} \mathrm{C}_{2}}$} & \multicolumn{2}{|c|}{ Optimal parameters(estimated \& experimental) } \\
\hline & & $\mathrm{A}_{2}, \mathrm{~B}_{1}, \mathrm{C}_{2}$ & $\mathrm{~A}_{2} \mathrm{~B}_{1} \mathrm{C}_{2}$ \\
\hline & & Estimated & Experimental \\
\hline Tensile Strength $\left(\mathrm{N} / \mathrm{mm}^{2}\right)$ & 185.00 & 323.33 & 352.29 \\
\hline S/N Ratio & 44.20 & 50.19 & 53.39 \\
\hline Joint Efficiency \% & 35.31 & 60.94 & 67.04 \\
\hline
\end{tabular}

Table VIII: Results of Confirmation test of welded joint using cylindrical Tool with groove.

\begin{tabular}{|c|c|c|c|}
\hline \multirow{2}{*}{} & Initial parameters & \multicolumn{2}{|c|}{ Optimal parameters(estimated \& experimental) } \\
\cline { 2 - 4 } & $\mathrm{A}_{2} \mathrm{~B}_{2} \mathrm{C}_{2}$ & $\mathrm{~A}_{3} \mathrm{~B}_{2} \mathrm{C}_{2}$ & $\mathrm{~A}_{3} \mathrm{~B}_{2} \mathrm{C}_{2}$ \\
\cline { 2 - 4 } & 240.00 & Estimated & Experimental \\
\hline Tensile Strength $\left(\mathrm{N} / \mathrm{mm}^{2}\right)$ & 40.21 & 281.45 & 508.92 \\
\hline S/N Ratio & 45.80 & 48.06 & 70.40 \\
\hline Joint Efficiency \% & 61.70 & \\
\hline
\end{tabular}

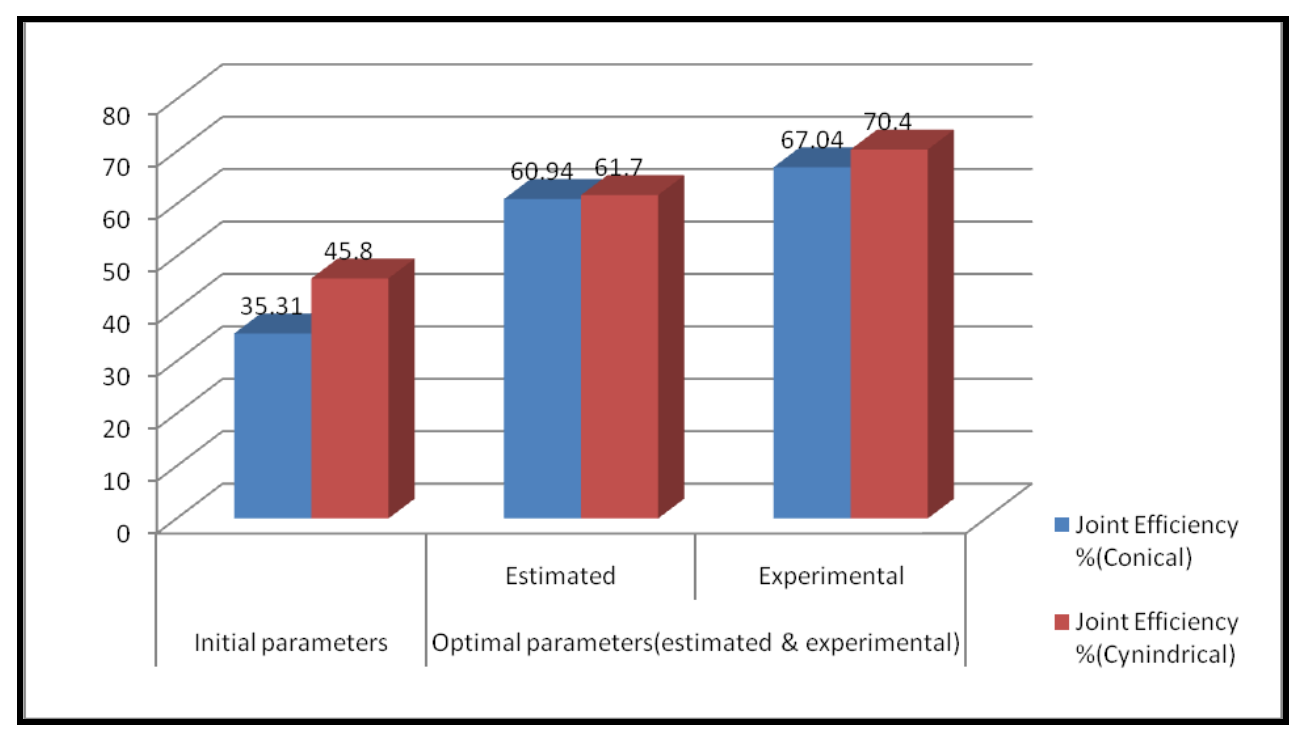

Figure 10: Efficiency of welded joints.

It is observed on comparison, that there is a good agreement between the estimated and experimental tensile strength of welded joint.

\section{CONCLUSIONS}

In this investigation it was found that, Taguchi approach can be successfully applied to determine optimum value of process parameters like tool rotational speed, weld traverse speed and plunge depth on the tensile strength of the AA 7075-T6 aluminum alloy welds 
produced by FSW method using conical and cylindrical tool within the range of selected values of process parameters.

The percentage contribution of these process parameters were determined by ANOVA and it was found that the tool rotational speed and weld traverse speed are the important factors contributing to the response.

The method described in this paper for the prediction of tensile strength and optimization of process parameter can eliminate the need for performing more experiments on the basis of conventional trial and error method to achieve the same.

\section{ACKNOWLEDGEMENT}

Authors are thankful to Prof. Satish V Kailas, Professor, Department of Mechanical Engineering, IIsc, Bangalore for extending facilities of FSW setup to carry out this investigation. The authors wish to express sincere thanks to Aeronautical Research \& Development Board (ARDB), New Delhi, for financial support rendered through R\& D project No: DARO/08/2031473/M/I.

\section{REFERENCES}

[1] Y. S. Sato et al. (2003) Friction stir welding (FSW) process welding international, 17 (11) $852-$ 855

[2] FU Zhi-hong et al. (2004) Friction stir welding of Aluminum Alloys Journal of Wuhan University of Technology - Mater. Sci. Ed, Mar., Vol. 19, No. 1, 61-64

[3] A.Hartawan, et al. (2009) Initial investigation into friction stir welding SIM tech. technical reports (STR_V10_N1_02_MTG), Volume 10,Number 1, Jan-march, 5-9

[4] T. Venugopal, et al. (2004) Studies on friction stir welded AA 7075 aluminum alloy Trans. Indian Inst. Met. Vol.57, No. 6, , pp. 659-663 T NOTE

[5] V. Balasubramanian et al. (2007) Relationship between base metal properties and Friction Stir Welding process Journal of Material Science Engineering, A

[6] A. K. Lakshminaryan et al. (2009) Effect of Welding process on tensile properties of AA6061 aluminum alloy joints International Journal of Advanced Manufacturing Technology , 40. 286296

[7] K. Elangovan et al. (2007) Influence of pin profile and rotational speed of the tool on the formation of friction processing zone Journal of Material Science Engineering A, 459, 7-18

[8] K. Elangovan et.al. (2008) Influences of tool pin profile and axial force on the formation of friction stir processing zone in AA6061 aluminium alloy International Journal Advanced Manufacturing Technology 38:285-295 DOI 10.1007/s00170-007-1100-2

[9] K. Kumar et al. (2008) Influence of Tool Geometry in friction Stir Welding International Journal of Materials and Manufacturing Process, 23. 188-194 23: 188-194, DOI: 10.1080/10426910701774734

[10] K Elangovan et al. (2008) Optimizing of Friction Stir welding parameters to maximize the tensile strength of AA6061 aluminum alloy joints International Journal of Manufacturing Research, vol 3,No.3, ,321-334

[11] Montogomery D. C.: Design and analysis of Experiments[M] IV edition, John -Viley \& Sons Inc, NY

[12] Ross P. J.: (1998) Taguchi Techniques for quality Engineering [M]" NY, Tata Mc Graw Hill

[13] ASTM standards

[14] MINITAB software

[15] Win Robust software 